\title{
A Pattern of Care Report on the Management of Patients with Squamous Cell Carcinoma of the Anus-A Study by the Italian Association of Radiotherapy and Clinical Oncology (AIRO) Gastrointestinal Tumors Study Group
}

\author{
Pierfrancesco Franco ${ }^{1,2, *(\mathbb{D})}$, Giuditta Chiloiro ${ }^{3}{ }^{\circ}$, Giampaolo Montesi ${ }^{4}$, Sabrina Montrone 5 , \\ Alessandra Arcelli ${ }^{6,7} \oplus$, Tiziana Comito ${ }^{8}$, Francesca Arcadipane ${ }^{9}$, Luciana Caravatta ${ }^{10}{ }^{\circledR}$, Gabriella Macchia ${ }^{11}{ }^{1}$, \\ Marco Lupattelli ${ }^{12}$, Marina Rita Niespolo ${ }^{13}$, Fernando Munoz ${ }^{14}\left(\mathbb{D}\right.$, Elisa Palazzari ${ }^{15}$, Marco Krengli ${ }^{1,2}{ }^{\mathbb{D}}$, \\ Francesca Valvo ${ }^{16}$, Maria Antonietta Gambacorta ${ }^{3}$, Domenico Genovesi ${ }^{10,17}$ and Giovanna Mantello ${ }^{18}$
}

check for
updates

Citation: Franco, P.; Chiloiro, G.;

Montesi, G.; Montrone, S.; Arcelli, A.;

Comito, T.; Arcadipane, F.; Caravatta,

L.; Macchia, G.; Lupattelli, M.; et al. A

Pattern of Care Report on the

Management of Patients with

Squamous Cell Carcinoma of the

Anus-A Study by the Italian

Association of Radiotherapy and

Clinical Oncology (AIRO)

Gastrointestinal Tumors Study Group.

Medicina 2021, 57, 1342. https://

doi.org/10.3390/medicina57121342

Academic Editor:

Ludovico Abenavoli

Received: 11 October 2021

Accepted: 6 December 2021

Published: 9 December 2021

Publisher's Note: MDPI stays neutral with regard to jurisdictional claims in published maps and institutional affiliations.

Copyright: (C) 2021 by the authors. Licensee MDPI, Basel, Switzerland. This article is an open access article distributed under the terms and conditions of the Creative Commons Attribution (CC BY) license (https:/ / creativecommons.org/licenses/by/ $4.0 /)$
1 Department of Translational Medicine, University of Eastern Piedmont, Via Solaroli 17, 28100 Novara, Italy; marco.krengli@med.uniupo.it

2 Department of Radiation Oncology, 'Maggiore della Carita' University Hospital, Via Solaroli 17, 28100 Novara, Italy

3 Fondazione Policlinico Universitario 'Agostino Gemelli' IRCCS, Via della Pineta Sacchetti, 00168 Rome, Italy; giuditta.chiloiro@policlinicogemelli.it (G.C.); mariaantonietta.gambacorta@policlinicogemelli.it (M.A.G.)

4 Radiation Oncology Department, 'S.M. Della Misericordia' Hospital, AULSS 5 Veneto, Viale Tre Martiri 140, 45100 Rovigo, Italy; giampaolo.montesi@aulss5.veneto.it

5 Radiation Oncology Unit, Pisa University Hospital, Via Roma 67, 56123 Pisa, Italy; sabrina.montrone@ao-pisa-toscana.it

6 Radiation Oncology Unit, IRCCS Azienda Ospedaliero-Universitaria di Bologna, Via Massarenti 9 , 40138 Bologna, Italy; alessandra.arcelli2@unibo.it

7 Department of Experimental, Diagnostic and Specialty Medicine-DIMES, Alma Mater Studiorum, Bologna University, Via Massarenti 9, 40138 Bologna, Italy

8 Radiotherapy Department, Humanitas Clinical and Research Hospital IRCCS, Via Manzoni 56, Rozzano, 20089 Milan, Italy; tiziana.comito@cancercenter.humanitas.it

9 Department of Oncology, Radiation Oncology, AOU 'Citta' della Salute e della Scienza', Via Cavour 31, 10123 Turin, Italy; farcadipane@cittadellasalute.to.it

10 Radiation Oncology Unit, 'SS Annunziata Hospital', 'G. D'Annunzio' University of Chieti-Pescara, Via dei Vestini, 66100 Chieti, Italy; luciana.caravatta@asl2abruzzo.it (L.C.); d.genovesi@unich.it (D.G.)

11 Radiation Oncology Unit, Gemelli Molise Hospital-Universita' Cattolica del Sacro Cuore, Largo Agostino Gemelli 1, 86100 Campobasso, Italy; gabriella.macchia@gemellimolise.it

12 Radiation Oncology Section, Perugia General Hospital, Piazzale Meneghini 1, 06156 Perugia, Italy; marco.lupattelli@ospedale.perugia.it

13 Department of Radiation Oncology, Azienda Ospedaliera S. Gerardo, Via Pergolesi 33, 20900 Monza, Italy; r.niespolo@hsgerardo.org

14 Radiation Oncology Department, 'Umberto Parini' Regional Hospital, AUSL Valle d'Aosta, Aosta, Viale Ginevra 3, 11100 Aosta, Italy; FMunoz@ausl.vda.it

15 Radiation Oncology Department, Oncological Referral Center, Via Gallini 2, 33081 Aviano, Italy; elisa.palazzari@cro.it

16 Scientific Direction Unit, National Center for Oncological Hadrontherapy (CNAO), Strada Campeggi 53, 27100 Pavia, Italy; francesca.valvo@cnao.it

17 Department of Neuroscience, Imaging and Clinical Sciences, 'G.D'Annunzio', University of Chieti-Pescara, Via dei Vestini 31, 66100 Chieti, Italy

18 Department of Oncology and Radiotherapy, Azienda Ospedaliero Universitaria Ospedali Riuniti, Via Conca 71, Torrette, 60002 Ancona, Italy; giovanna.mantello@ospedaliriuniti.marche.it

* Correspondence: pierfrancesco.franco@uniupo.it; Tel.: +39-032137-33-424

Abstract: Background and objectives: The diagnosis and therapy of squamous cell carcinoma of the anus may vary significantly in daily clinical practice, even if international guidelines are available. Materials and Methods: We conducted a pattern of care survey to assess the management of patients with anal cancer in Italy (38 questions). We analyzed 58 questionnaires. Results: Most of the respondents work in public and/or university hospitals $(75.8 \%)$ in northern Italy $(65.5 \%)$. The majority $(88.0 \%)$ treat less than 20 patients/year. Common examinations for diagnosis and staging are anorectal endoscopy $(84.5 \%)$, computed tomography scan $(86.2 \%)$ and pelvic magnetic resonance imaging (MRI) $(96.5 \%)$. 
The most frequently prescribed dose to primary tumor is 50-54 Gy (46.5-58.6\%) for early stage disease and 54-59.4 Gy (62.1-32.8\%) for locally advanced cases. Elective volumes are prescribed around $45 \mathrm{~Gy}$ (94.8\%). Most participants use volumetric intensity modulated radiotherapy (89.7\%) and a simultaneous integrated boost $(84.5 \%)$. Concurrent radiotherapy, 5-fluorouracil and mitomycin is considered the standard of care $(70.6 \%)$. Capecitabine is less frequently used $(34.4 \%)$. Induction chemotherapy is an option for extensive localized disease $(65.5 \%)$. Consolidation chemotherapy is rarely used $(18.9 \%)$. A response evaluation is conducted at $26-30$ weeks $(63.9 \%)$ with a pelvic MRI (91.4\%). Follow-up is generally run by the multidisciplinary tumor board (62.1\%). Conclusions: Differences were observed for radiotherapy dose prescription, calling for a consensus to harmonize treatment strategies.

Keywords: anal cancer; squamous cell carcinoma; anus; chemoradiation; radiotherapy; pattern of care

\section{Introduction}

The standard therapeutic option for patients with non-metastatic squamous cell carcinoma (SCC) of the anus comprises of a combined modality treatment with concurrent chemoradiation based on 5-fluorouracil (5-FU) and mitomycin C (MMC) [1-3]. In the setting of advanced and/or metastatic disease, various chemotherapy regimens are available, leading to different outcome results and toxicity profiles [4,5]. Radiotherapy (RT) delivery is based on intensity modulated radiotherapy (IMRT), usually supported by image guidance (IGRT) [6,7]. Several national and international guidelines provide indications for diagnosis, staging, treatment and follow-up [8-12]. In 2014, the Italian Association for Radiotherapy and Clinical Oncology (AIRO), developed national guidelines dedicated to the RT treatment of tumors of the gastrointestinal tract, including SCC of the anus, to optimize and homogenize treatment approaches within the Italian radiation oncology community [13]. Nevertheless, a recent retrospective observational study performed by the Gastrointestinal Tumors Study Group of AIRO reported some degree of heterogeneity in terms of RT dose prescription, treatment volume selection and definition, delivery approaches and preference of different combination therapy modalities [14]. To provide a backbone for the update of the Italian national guidelines and to harmonize treatment recommendations for anal cancer in Italy, we ideated and conducted a national survey to shed light on how patients with SCC of the anal canal are currently diagnosed and treated in the country. We report on the results of the survey, framing them within the available evidence for the diagnosis and treatment of anal SCC.

\section{Materials and Methods}

The project was developed within the Study Group for Gastrointestinal Tumors of AIRO, whose Directive Council acted as a steering committee. An external panel of radiation oncologists with a specific expertise in the management of anal cancer provided suggestions and comments. Face validity, together with the content, wording and general flow of the survey was internally evaluated. An online cross-sectional survey was carried out using Survey Monkey (www.surveymonkey.com; accessed on 28 March 2021), with an automatic method for capturing responses. Usability and technical functionality of the electronic form was assessed before fielding the questionnaire. No personal information was collected. Professional information was stored within the Survey Monkey platform and protected from unauthorized access, as compliant with the platform regulatory. The project was approved by the Scientific Council and the Board of Directors of AIRO. Participants were invited to participate voluntarily (February-March 2021) via email, after identification as members of AIRO. The invitation was sent by the Secretariat of AIRO. One reminder was sent during the study period. No explicit informed consent was requested. No incentive was offered. The only two requirements to be eligible to participate in the 
survey were to work as a radiation oncologist and to be an active member of AIRO with an expertise in the treatment of gastrointestinal malignancies including anal cancer. The survey was set as a 'closed survey' with a selection of participants upon invitation. The initial contact mode to the participant was made via Internet. The initiative was announced and advertised through the network of AIRO using both its mailing list and website. The English translation of the exact wording used for the announcement can be found in the Supplementary Materials. One radiation oncologist per center was allowed to participate in the survey. Demographics and professional information useful for stratification were collected. The questionnaire consisted of 38 questions, some of them allowing for multiple answers and comments, and covering diagnosis and treatment of SCC of the anal canal and margin (Supplementary Materials). Statistical analysis was provided by www.surveymonkey.com (accessed on 28 March 2021) and included a description of all variables. Responses were tabulated, and the percentage values reported. The survey was compliant with the CHERRIES guidelines for reporting results of internet e-surveys [15].

\section{Results}

Among the 165 RT departments documented in Italy by AIRO who were invited (as per 2018), a total of 71 centers (43\%) participated in the present survey. Among them, 58 participants $(82 \%)$ fully completed the questionnaires and their answers were considered for the current analysis. Detailed characteristics of the participants and centers can be found in Table 1. Most of the respondents work in public and/or university hospitals (75.8\%) in the northern part of the country $(65.5 \%)$. The clinical experience of the participants was almost equally split between below (48.3\%) and above (51.7) 10 years. The vast majority of the centers $(88.0 \%)$ treats less than 20 anal cancer patients per year.

Table 1. Characteristics of the participants and centers.

\begin{tabular}{cc}
\hline Radiotherapy Facility & N (\%) \\
\hline Public & $30(51.7)$ \\
Accredited private hospital & $7(12.1)$ \\
University Hospital & $14(24.1)$ \\
Accredited cancer center (IRCCS) & $7(12.1)$ \\
Operating region in Italy & \\
Northern Italy & $38(65.5)$ \\
Central Italy & $13(22.4)$ \\
Southern Italy & $7(12.1)$ \\
Years of experience in RT & \\
$<5$ & $10(17.2)$ \\
$5-10$ & $18(31.1)$ \\
$11-15$ & $9(15.5)$ \\
$>15$ & $21(36.2)$ \\
$<10$ & $23(39.7)$ \\
$11-20$ & $28(48.3)$ \\
$21-30$ & $6(10.3)$ \\
$>30$ & $1(1.7)$ \\
Anal cancer patients treated/year & $54(93.1)$ \\
Yes & $4(6.9)$ \\
No &
\end{tabular}

Legend: N: number; IRCCS: Istituto di Ricovero e Cura a carattere scientifico; RT: radiotherapy; MDT: Multidisciplinary Team.

\subsection{Diagnosis and Staging}

See Table 2 for details. With respect to diagnosis and staging, the most commonly prescribed examinations are anorectal endoscopy $(84.5 \%)$, contrast-enhanced computed tomography (CT) scan of the thorax and abdomen $(86.2 \%)$ and pelvic magnetic resonance imaging (MRI) (96.5\%). Pelvic MRI is considered as a mandatory examination for diagnosis and staging by most of the respondents (86.2\%), while 18-fluorodeoxyglucose-positron 
emission tomography (FDG-PET) is mostly deemed as an optional or second-level examination $(62.1 \%)$. Biopsy confirmation of a suspected inguinal lymph node is limited to cases with low or no metabolic uptake at functional imaging $(60.3 \%)$. Screening for the human immunodeficiency virus is undertaken by half of the respondents $(50.0 \%)$ by default, while determination of the human papilloma virus is consistently carried out by more than a half of the participants (58.6\%). Multidisciplinary team discussion is considered standard by $87.9 \%$ of the centers.

Table 2. Diagnosis and staging.

\begin{tabular}{|c|c|}
\hline Staging Examinations (Multiple Answers Allowed) & $\mathbf{N}(\%)$ \\
\hline Rigid anal-rectal endoscopy & $49(84.5)$ \\
\hline Colonoscopy & $30(51.7)$ \\
\hline GYN evaluation + colposcopy & $13(22.4)$ \\
\hline Contrast-enhanced CT scan (thorax-abdomen) & $50(86.2)$ \\
\hline Pelvic MRI & $56(96.5)$ \\
\hline Whole-body ${ }^{18}$ FDG-PET & $39(67.2)$ \\
\hline Endoscopic ultrasound & $19(32.8)$ \\
\hline \multicolumn{2}{|l|}{ Attitude towards pelvic MRI at diagnosis } \\
\hline Mandatory & $50(86.2)$ \\
\hline Optional but useful & $6(10.3)$ \\
\hline Second-level examination & $2(3.5)$ \\
\hline Useless & $0(0)$ \\
\hline \multicolumn{2}{|l|}{ Attitude towards ${ }^{18}$ FDG-PET at diagnosis } \\
\hline Mandatory & $22(37.9)$ \\
\hline Optional but useful & $20(34.5)$ \\
\hline Second-level examination & $16(27.6)$ \\
\hline Useless & $0(0)$ \\
\hline \multicolumn{2}{|l|}{ Inguinal biopsy/fine needle aspiration of suspicious node } \\
\hline Always & $3(5.2)$ \\
\hline $\begin{array}{l}\text { Only if clinically palpable lymph node detected on CT (size }>1 \mathrm{~cm}) \text { and } \\
\qquad{ }_{18} \text { FDG-PET avidity }\end{array}$ & $1(1.7)$ \\
\hline $\begin{array}{c}\text { Only in case of clinically palpable lymph node detected on CT }(\text { size }>1 \mathrm{~cm}) \\
\text { and borderline }{ }^{18} \text { FDG-PET avidity }\end{array}$ & $30(51.7)$ \\
\hline $\begin{array}{c}\text { Only in case of clinically palpable lymph node detected on CT }(\text { size }>1 \mathrm{~cm}) \\
\text { without }{ }^{18} \text { FDG-PET avidity }\end{array}$ & $5(8.6)$ \\
\hline Never & $19(32.8)$ \\
\hline \multicolumn{2}{|l|}{ HIV screening (on blood or saliva) } \\
\hline Always & $29(50.0)$ \\
\hline Sometimes & $16(27.6)$ \\
\hline Only in case of risk factors & $7(12.1)$ \\
\hline Never & $6(10.3)$ \\
\hline \multicolumn{2}{|l|}{ (HPV) p16 IHC detection on biopsy specimen } \\
\hline Always & $34(58.6)$ \\
\hline Sometimes & $21(36.2)$ \\
\hline Only in young patients & $0(0)$ \\
\hline Only in clinical trials & $3(5.2)$ \\
\hline Never & $0(0)$ \\
\hline \multicolumn{2}{|l|}{ Role of the multidisciplinary team } \\
\hline Standard approach for all patients & $51(87.9)$ \\
\hline Necessary only in selected cases & $5(8.6)$ \\
\hline Not applicable to my clinical practice & $2(3.5)$ \\
\hline
\end{tabular}

Legend: N: number; GYN: gynecological; CT: computed tomography; MRI: magnetic resonance imaging. FDG-PET: fluorodeoxyglucose positron emission tomography; HIV: human immunodeficiency virus; HPV: human papilloma virus; IHC: immunohistochemistry.

\subsection{Radiotherapy Dose Prescription and Delivery}

See Table 3 for details. To properly define the primary gross tumor volume (GTV), most of the participants employ MRI (89.7\%) and/or FDG-PET (77.6\%). The most frequently prescribed dose to primary GTV is around $50 \mathrm{~Gy}(46.5 \%)$ and $54 \mathrm{~Gy}(58.6 \%)$ for T1-T2 tumors and around $54 \mathrm{~Gy}(62.1 \%)$ or up to $59.4 \mathrm{~Gy}(32.8 \%)$ for T3-T4 disease. Nodal 
disease was mostly prescribed around 50 Gy if sized below $3 \mathrm{~cm}(58.6 \%)$ or around $55 \mathrm{~Gy}$ $(86.2 \%)$ if sized above. Elective volumes are mostly prescribed around 45 Gy $(94.8 \%)$. Most of the participants use volumetric intensity modulated radiotherapy techniques $(89.7 \%)$ and employ a simultaneous integrated boost to deliver extra doses to the primary tumor $(84.5 \%)$.

Table 3. Radiotherapy dose prescription and delivery.

\begin{tabular}{|c|c|}
\hline $\begin{array}{l}\text { Imaging for GTV Definition (Both Primary Tumor and Lymph Nodes) } \\
\text { (Multiple Answers Allowed) }\end{array}$ & N (\%) \\
\hline Planning CT & $8(13.8)$ \\
\hline Pelvic CT & $19(32.8)$ \\
\hline Pelvic MRI & $52(89.7)$ \\
\hline${ }^{18}$ FDG-PET & $45(77.6)$ \\
\hline \multicolumn{2}{|l|}{ RT delivery technique (multiple answers allowed) } \\
\hline 3DCRT & $0(0)$ \\
\hline IMRT & $10(17.2)$ \\
\hline Volumetric IMRT & $52(89.7)$ \\
\hline Tomotherapy & $12(20.7)$ \\
\hline MRgRT & $0(0)$ \\
\hline \multicolumn{2}{|l|}{ Primary tumor boost (multiple answers allowed) } \\
\hline EBRT-Sequential boost & $26(44.8)$ \\
\hline EBRT-SIB & $49(84.5)$ \\
\hline EBRT-Electrons & $2(3.4)$ \\
\hline Endocavitary or Contact BRT & $3(5.2)$ \\
\hline Interstitial BRT & $4(6.9)$ \\
\hline \multicolumn{2}{|l|}{ Treatment after local excision for T1N0 tumor with risk factors } \\
\hline Exclusive RT with definitive dose & $21(36.2)$ \\
\hline RT-CHT with RT dose de-escalation & $13(22.4)$ \\
\hline RT-CHT with definitive RT dose & $17(29.3)$ \\
\hline RT with dose de-escalation & $2(3.5)$ \\
\hline Others & $5(8.6)$ \\
\hline \multicolumn{2}{|l|}{$\begin{array}{l}\text { RT dose to primary tumor GTV for T1-T2 tumors (dose range) } \\
\text { (multiple answers allowed) }\end{array}$} \\
\hline $45-45.9 \mathrm{~Gy}$ & $2(3.5)$ \\
\hline $50-50.4$ Gy & $27(46.5)$ \\
\hline $54-55$ Gy & $34(58.6)$ \\
\hline $56-59.4$ Gy & $7(12.1)$ \\
\hline$\geq 60$ Gy & $4(6.9)$ \\
\hline \multicolumn{2}{|l|}{$\begin{array}{l}\text { RT dose to primary tumor GTV for T3-T4 tumors (dose range) } \\
\text { (multiple answers allowed) }\end{array}$} \\
\hline $53 \mathrm{~Gy}$ & $1(1.7)$ \\
\hline $54-55.5$ Gy & $36(62.1)$ \\
\hline $56-59.4$ Gy & $19(32.8)$ \\
\hline$\geq 60 \mathrm{~Gy}$ & $13(22.4)$ \\
\hline \multicolumn{2}{|l|}{ Dose to elective volumes (multiple answers allowed) } \\
\hline $30.6 \mathrm{~Gy}$ & $1(1.7)$ \\
\hline 36-37.5 Gy & $2(3.5)$ \\
\hline $42-42.5 \mathrm{~Gy}$ & $5(8.6)$ \\
\hline $45-45.9 \mathrm{~Gy}$ & $55(94.8)$ \\
\hline 49.5-50.4 Gy & $11(18.9)$ \\
\hline$>54 \mathrm{~Gy}$ & $3(5.2)$ \\
\hline \multicolumn{2}{|l|}{ Dose to involved nodes (sized $<3 \mathrm{~cm}$ ) (multiple answers allowed) } \\
\hline $40 \mathrm{~Gy}$ & $1(1.7)$ \\
\hline $45 \mathrm{~Gy}$ & $1(1.7)$ \\
\hline $50-51 \mathrm{~Gy}$ & $34(58.6)$ \\
\hline $52-53.2 \mathrm{~Gy}$ & $6(10.3)$ \\
\hline
\end{tabular}


Table 3. Cont.

\begin{tabular}{cc}
\hline $\begin{array}{c}\text { Imaging for GTV Definition (Both Primary Tumor and Lymph Nodes) } \\
\text { (Multiple Answers Allowed) }\end{array}$ & N (\%) \\
\hline $54-56 \mathrm{~Gy}$ & $19(32.8)$ \\
$59-59.4 \mathrm{~Gy}$ & $2(3.5)$ \\
$\geq 60 \mathrm{~Gy}$ & $4(6.9)$ \\
& \\
Dose to involved nodes (sized $>3 \mathrm{~cm}$ ) (multiple answers allowed) & $1(1.7)$ \\
$45 \mathrm{~Gy}$ & $4(6.9)$ \\
$50-50.4 \mathrm{~Gy}$ & $2(3.5)$ \\
$52-52.5 \mathrm{~Gy}$ & $50(86.2)$ \\
$54-56 \mathrm{~Gy}$ & $3(5.2)$ \\
$59-59.4 \mathrm{~Gy}$ & $5(8.6)$ \\
$\geq 60$ Gy & \\
\hline Legend: N: number; GTV: gross tumor volume; RT: radiotherapy; CT: computed tomography; MRI: magnetic \\
resonance imaging; ${ }^{18}$ FDG-PET: fluorodeoxyglucose positron emission tomography; 3DCRT: 3-dimensional con- \\
formal radiotherapy; IMRT: intensity modulated radiotherapy; MRgRT: magnetic resonance guided radiotherapy; \\
EBRT: external beam radiotherapy; SIB: simultaneous integrated boost; BRT: brachytherapy; CHT: chemotherapy.
\end{tabular}

\subsection{Combination Therapy}

See Table 4 for details. Most of the participants (70.6\%) consider concurrent RT and 5FU-MMC as standard of care in anal cancer patients. Two cycles are normally administered (81.0\%) with an MMC dose of $10 \mathrm{mg} / \mathrm{m}^{2}$. Capecitabine is considered standard of care by $34.4 \%$ of respondents, while cisplatin (CDDP) is mostly used in cases of clinical contraindication to MMC (70.7\%). Induction chemotherapy is considered a viable option in cases of extensive localized disease (65.5\%), mainly with 5FU-CDDP (56.9\%). Consolidation chemotherapy is rarely used (18.9\%), mostly with 5FU-CDDP (6.9\%). The most commonly prescribed chemotherapy regimen for advanced or metastatic disease is CDDP-5FU (62\%). HIV-positive patients are treated with standard concurrent chemoradiation in cases of normal CD4 positive count (39.6\%), eventually requiring undetectable viral RNA (20.7\%).

Table 4. Combined modality treatment.

\begin{tabular}{|c|c|}
\hline CHT Regimens Concurrent to RT & $\mathbf{N}(\%)$ \\
\hline 5FU-MMC & $41(70.6)$ \\
\hline 5FU-CDDP & $3(5.2)$ \\
\hline Cape-MMC & $11(19.0)$ \\
\hline Cape-CDDP & $1(1.7)$ \\
\hline Others & $2(3.5)$ \\
\hline \multicolumn{2}{|l|}{ Number of MMC cycles in cases of 5FU-MMC or Cape-MMC } \\
\hline 1 cycle (week 1 of RT) & $9(15.5)$ \\
\hline 2 cycles (week $5-6$ of RT) & $47(81.0)$ \\
\hline Other & $2(3.5)$ \\
\hline \multicolumn{2}{|l|}{ MMC dose in cases of 5FU-MMC or Cape-MMC ( 1 MMC cycle) } \\
\hline $10 \mathrm{mg} / \mathrm{m}^{2}$ & $21(80.7)$ \\
\hline $12 \mathrm{mg} / \mathrm{m}^{2}$ & $2(7.8)$ \\
\hline $10-12 \mathrm{mg} / \mathrm{m}^{2}$ & $3(11.5)$ \\
\hline \multicolumn{2}{|l|}{ MMC dose in cases of 5FU-MMC or Cape-MMC ( 2 MMC cycle) } \\
\hline $10 \mathrm{mg} / \mathrm{m}^{2}$ & $31(91.2)$ \\
\hline $12 \mathrm{mg} / \mathrm{m}^{2}$ & $1(2.9)$ \\
\hline $10-12 \mathrm{mg} / \mathrm{m}^{2}$ & $2(5.9)$ \\
\hline \multicolumn{2}{|l|}{ Screening for DPYD genotype } \\
\hline Yes & $46(79.3)$ \\
\hline No & $12(20.7)$ \\
\hline \multicolumn{2}{|l|}{ Use of Cape concurrent to MMC or CDDP and RT } \\
\hline Standard of care (daily practice) & $20(34.4)$ \\
\hline Investigational (within clinical trial only) & $4(6.9)$ \\
\hline Upon patient's preference or in case of challenges for CVC placement & $32(55.2)$ \\
\hline Other & $2(3.5)$ \\
\hline
\end{tabular}


Table 4. Cont.

\begin{tabular}{|c|c|}
\hline CHT Regimens Concurrent to RT & $\mathbf{N}(\%)$ \\
\hline \multicolumn{2}{|l|}{ Use of CDDP as alternative to MMC concurrent to $5 \mathrm{FU}$ or Cape and RT } \\
\hline Equivalent to MMC & $8(13.8)$ \\
\hline Inferior to MMC & $8(13.8)$ \\
\hline Only in case of clinical contraindication to MMC & $41(70.7)$ \\
\hline Other & $1(1.7)$ \\
\hline \multicolumn{2}{|l|}{ Use of induction chemotherapy } \\
\hline Standard & $1(1.7)$ \\
\hline Not standard & $19(32.8)$ \\
\hline Only in case of extensive pelvic involvement or extra-pelvic disease & $38(65.5)$ \\
\hline Other & $0(0)$ \\
\hline \multicolumn{2}{|l|}{ Use of consolidation CHT after RT-CHT } \\
\hline Standard & $0(0)$ \\
\hline Not standard & $44(75.9)$ \\
\hline $\begin{array}{c}\text { In case of high-risk disease (locally advanced tumors with nodal } \\
\text { involvement) }\end{array}$ & 11 (18.9) \\
\hline Other & $3(5.2)$ \\
\hline \multicolumn{2}{|l|}{$\mathrm{CHT}$ regimen for induction $\mathrm{CHT}$} \\
\hline 5FU-CDDP & $33(56.9)$ \\
\hline 5FU-MMC & $17(29.3)$ \\
\hline Other & $4(6.9)$ \\
\hline None & $4(6.9)$ \\
\hline \multicolumn{2}{|l|}{$\mathrm{CHT}$ regimen for consolidation $\mathrm{CHT}$} \\
\hline 5FU-CDDP & $4(6.9)$ \\
\hline 5FU-MMC & $3(5.2)$ \\
\hline Other & $4(6.9)$ \\
\hline None & $47(81.0)$ \\
\hline \multicolumn{2}{|l|}{ Type of definitive RT-CHT in HIV+ve patients submitted to HAART } \\
\hline Standard CHT-RT & $12(20.7)$ \\
\hline Standard CHT-RT in patient with normal CD4+ve count & $23(39.6)$ \\
\hline $\begin{array}{c}\text { Standard CHT-RT in patient with normal CD4+ve count and undetectable } \\
\text { viral RNA }\end{array}$ & $12(20.7)$ \\
\hline CHT dose reduction & $4(6.9)$ \\
\hline Use of alternative $\mathrm{CHT}$ regimens (i.e., CDDP over MMC) & $7(12.1)$ \\
\hline \multicolumn{2}{|l|}{ Standard first-line chemotherapy for advanced or metastatic disease } \\
\hline CDDP-5FU & $36(62.0)$ \\
\hline CBDCA + paclitaxel & $19(32.8)$ \\
\hline (Modified) Docetaxel + CDDP $+5 \mathrm{FU}$ & $3(5.2)$ \\
\hline
\end{tabular}

Legend: N: number; CHT: chemotherapy; RT: radiotherapy; 5FU: 5-fluorouracil; Cape: capecitabine; MMC: mitomycin C; CDDP: cisplatin; Mg: milligrams; $\mathrm{M}^{2}$ : square meters; DPYD: dihydropyrimidine dehydrogenase; CVC: central venous catheter; HIV: human immunodeficiency virus; +ve: positive; HAART: highly active antiretroviral therapy; CD4: cluster of differentiation 4; RNA: ribonucleic acid; CBDCA: carboplatin.

\subsection{Response Assessment, Salvage Therapies and Follow-Up}

See Table 5 for details. Most of the participants perform a response evaluation at 26-30 weeks (63.9\%), with a pelvic MRI (91.4\%) and/or FDG-PET (58.6\%). Biopsy assessment is only performed in cases of suspected residual disease (53.4\%). Surgery is considered as a salvage curative option for persistent/recurrent disease by $93.0 \%$ of respondents, after discussion within the tumor board (62.1\%). Follow-up and survivorship is managed by the radiation oncologist in $60.3 \%$ of the cases. The follow-up protocol is generally (60.3\%) more intense during the first 2 years after treatment (every 3 months) and less frequent in the following 3 years (every 6 months). 
Table 5. Response assessment, salvage therapies and follow-up.

\begin{tabular}{|c|c|}
\hline Optimal Timing for Restaging After the End RT-CHT & $\mathbf{N}(\%)$ \\
\hline 8 weeks & $6(10.3)$ \\
\hline 3 months & $10(17.2)$ \\
\hline 6 months & $20(34.6)$ \\
\hline$>6$ months & $5(8.6)$ \\
\hline 26 weeks & $17(29.3)$ \\
\hline \multicolumn{2}{|l|}{$\begin{array}{c}\text { Imaging examination for restaging after RT-CHT (multiple answers } \\
\text { allowed) }\end{array}$} \\
\hline Abdomino-pelvic contrast-enhanced CT scan & $26(44.8)$ \\
\hline Pelvic contrast-enhanced MRI & $53(91.4)$ \\
\hline${ }^{18}$ FDG PET-CT & $34(58.6)$ \\
\hline Abdominal US & $20(34.5)$ \\
\hline \multicolumn{2}{|l|}{ Bioptic evaluation for response assessment } \\
\hline Always & $2(3.5)$ \\
\hline Only if persistent disease is suspected or a residual scar is present & $16(27.6)$ \\
\hline Only if persistent disease is suspected & $31(53.4)$ \\
\hline I decide according to tumor clearance during RT-CHT & $9(15.5)$ \\
\hline Never & $0(0)$ \\
\hline \multicolumn{2}{|l|}{ Opinion about salvage surgery for recurrent/persistent disease } \\
\hline Always curative & $14(24.1)$ \\
\hline Curative in about half of patients & $7(12.1)$ \\
\hline Never curative & $0(0)$ \\
\hline My opinion is normally validated by tumor board & $36(62.1)$ \\
\hline Other & $1(1.7)$ \\
\hline \multicolumn{2}{|l|}{ Treatment for local relapse } \\
\hline Exclusive surgery when feasible & $54(93.0)$ \\
\hline Re-irradiation $+\mathrm{CHT}$ with palliative intent & $0(0)$ \\
\hline Exclusive $\mathrm{CHT}$ & $2(3.5)$ \\
\hline Re-irradiation + pre-operative CHT + eventual surgery & $2(3.5)$ \\
\hline \multicolumn{2}{|l|}{ Management of late toxicity in long-term survivors } \\
\hline Conducted by the radiation oncologist & $35(60.3)$ \\
\hline Conducted by other specialists (medical oncologist, surgeon) & $2(3.5)$ \\
\hline Based on tumor board management & $21(36.2)$ \\
\hline \multicolumn{2}{|l|}{ Follow-up timing } \\
\hline Every 3 months for the first 5 years & $1(1.7)$ \\
\hline Every 6 months for the first 5 years & $2(3.5)$ \\
\hline Every 3 months for the first year then every 6 months for the next 4 years & $18(31.0)$ \\
\hline Every 3 months for the first 2 years then every 6 months for the next 3 years & $35(60.3)$ \\
\hline Other & $2(3.5)$ \\
\hline
\end{tabular}

Legend: N: number; RT: radiotherapy; CHT: chemotherapy; CT: computed tomography; MRI: magnetic resonance imaging; FDG-PET: fluorodeoxyglucose positron emission tomography; US: ultrasounds.

\section{Discussion}

This is the first survey exploring the pattern of care in Italy for the diagnosis and treatment of patients affected with SCC of the anus. With respect to pre-treatment and staging imaging modalities, thorax and abdominal CT, together with pelvic MRI, are prescribed by the vast majority of respondents ( $>85 \%$ ), while FDG-PET is used by two out of three participants. Pelvic MRI is considered a mandatory examination to be requested, in agreement with the updated European Society for Medical Oncology (ESMO) guidelines [8]. Conversely, FDG-PET is considered an optional or second-level examination by more than $60 \%$ of respondents. This is in line with the results of a recent survey carried out in German-speaking countries [16,17]. In the recent ESMO guidelines, FDG-PET is considered as an exam to be recommended, but not mandated [8]. It has to be noted that, apart from staging purposes, FDG-PET may be clinically useful to confirm or not suspicious features detected on MRI, to drive target volume selection and delineation and to define organs at risk for tailored IMRT approaches [18-20]. Interestingly, gynecological examination is performed by around one out of five participants, even if it is mandated in the ESMO 
guidelines during the diagnostic work-up [8]. The attitude toward the diagnostic biopsy of suspicious inguinal lymph nodes is rather cautious, with one out of three respondents never performing it and half of them requesting it in case of difficulties in the interpretation of the findings coming from morphologic and/or functional imaging. The latter approach is in line with the ESMO guidelines, suggesting a further characterization of enlarged inguinal nodes when confirmatory features of malignancy are lacking on either pelvic MRI or FDG/PET [8]. Routine HIV screening is performed by half of the centers participating in the survey, while around $40 \%$ would do it occasionally or in individuals at risk. The ESMO guidelines recommend testing in any individual whose lifestyle puts him/her at risk of contracting HIV infection, while NCCN guidelines suggest routine screening for HIV, since HIV-positive patients treated with highly active antiretroviral therapy may have similar treatment outcomes compared to HIV-negative patients [8,11,21]. The determination of $\mathrm{HPV}$, as measured directly or by means of the overexpression of the surrogate marker p16, is performed by more than $90 \%$ of the participants. This may be important in terms of prognostic stratification, since HPV negative tumors are less likely to respond to definitive treatments, while patients with HPV/p16 positive tumors have improved survival $[8,22]$. The use of IMRT techniques has been declared by all the participants, similarly to what has been reported in the German-speaking country survey and suggested by NCCN and European guidelines $[8,9,11]$. The use of simultaneous integrated boost (SIB) techniques to the primary tumor and macroscopic lymph nodes to deliver extra doses is common in our survey $(84.5 \%)$, even if almost half of respondents tend to employ also a sequential approach. Even in the absence of randomized data supporting the use of SIB, the RTOG 0529 trial, together with other mono-institutional series, suggest a trend towards a mild toxicity profile for IMRT and comparable oncological outcomes for SIB compared to a sequential boost [7,23-25]. Alternative boost techniques such as brachytherapy or contact therapy are used in few institutions. In our survey, we observed a rather large variability in terms of RT dose prescription, which reflects the corresponding heterogeneity present in the different national and international guidelines [8-12]. The most frequently prescribed total doses ranged between 50-55 Gy for early stage primary tumors and 54-59.4 Gy for advanced primaries. For involved lymph nodes, participants declared to prescribe doses around $50 \mathrm{~Gy}$ for small sized nodes and 54-56 Gy for larger nodes. The dose to elective nodal volumes is mostly around $45 \mathrm{~Gy}$. Differences in terms of prescription doses to the primary tumor do exist, ranging from the conventionally fractionated 50.4 Gy used in the ACT II trial in the UK, to the 55-59 Gy employed in the RTOG 9811 trial for locally advanced disease, and the 60 Gy reached within observational studies in Northern European countries [1,2,26]. Dose escalation was specifically evaluated within the ACCORD 03 prospective phase III trial, which showed no benefit for dose escalation beyond $60 \mathrm{~Gy}$, particularly when radiation dose is delivered with a time gap between the first phase of treatment and the sequential boost [27]. However, a recent pooled analysis of patient data enrolled in the ACCORD 03 and the KANAL phase 2 trials reported a total dose $>60$ Gy to be associated with better colostomy free survival [28]. The ongoing PLATO umbrella trial is currently assessing the efficacy and toxicity profile of risk-adapted RT dose prescription in anal cancer based on clinical staging [29]. In particular, the ACT4 study is a randomized phase II trial, targeting patients with early stage disease (T1, T2 up to $4 \mathrm{~cm}, \mathrm{~N} 0$ ) and comparing standard chemoradiation (50.4 Gy to the tumor, $40 \mathrm{~Gy}$ to the elective nodal region in 28 fractions $+5 \mathrm{FU}$ or capecitabine/MMC) with a reduced dose regimen (41.4 Gy and 34.5 Gy in 23 fractions, to primary tumor and elective volumes, respectively). The ACT5 trial targets patients with locally advanced tumors (T2N1-3 or T3/4Nany) and compared standard chemoradiation (53.2 Gy in 28 fractions + 5FU or capecitabine/MMC) with escalated regimens delivering a dose of either 58.8 or 61.6 Gy in 28 fractions. The aforementioned studies will help establish a risk-adapted radiotherapy dose prescription strategy in anal cancer. More than $90 \%$ of respondents usually deliver around 45 Gy to the elective volumes, which is in line with the recommendations of most guidelines [8-12]. Nevertheless, it has to be noted that the total dose prescribed in the ACT II trial to elective volumes was $30.6 \mathrm{~Gy}$, given 
with conventional fractionation, and that a recent report from the UK highlighted the oncological safety of delivering low total dose with low dose per fraction during SIB-based image-guided RT in this setting (40 Gy in 28 fractions; 1.43 Gy/daily) [1,30]. Concurrent RT and two cycles of 5FU-MMC is considered standard by most respondents, as in most of the international guidelines $[8,9,11,12]$. The role of the second infusion of MMC has been debated since it may not provide benefit in terms of oncologic outcomes, conversely adding extra adverse events, particularly in terms of hematologic toxicity [31,32]. The use of capecitabine is considered standard by one third of the respondents, which reflects the low evidence of the available clinical data mostly relying on relatively small series [8]. Nevertheless, the results of the UK national cohort seem reassuring with respect to the general oncological safety of the use of capecitabine [33]. Cisplatin is used concurrent to RT only in cases of contraindication to MMC by most respondents, as suggested in the national and international guidelines [8-12]. Induction and consolidation chemotherapy are not considered standard, even if two out of three of the participants may consider primary systemic therapy in cases of very advanced loco-regional disease. This probably comes with the knowledge that some cases with extra-pelvic disease may be converted to cure [34]. Most of the participants use the doublet 5FU-CDDP as first-line therapy for advanced/metastatic cases, while up to one third employ carboplatin and paclitaxel, which is now considered standard after the publication of the InterAAct trial [4]. Almost one third of respondents would perform a response assessment after definitive treatment at 26 weeks upon initiation of concurrent chemoradiation, approximately 5 months upon its completion. This is in line with the results of the ACT II trial [35]. Interestingly, another third of respondents would wait until 6 months from treatment end to assess response. This probably reflects the low response kinetics of some tumors, to be taken advantage of, particularly in the case of a good response trajectory. Pelvic MRI is the most commonly used imaging modality for response assessment, as recommended in the recent ESMO guidelines [4]. Bioptic confirmation is undertaken only in cases of the suspicion of persistent/recurrent disease. The most common approach to treat recurrent/persistent local disease is surgery, which, as recommended, should include an extralevator abdominoperineal excision [4]. The clinical follow-up strategy of treated patients is reported to be in line with the guideline recommendations, suggesting an evaluation every 3-6 months for a period of two years, and every 6-12 months until five years. During follow-up, it is crucial to evaluate and take care of eventual conditions affecting the anorectal and sexual function, together with urinary continence [4]. Treatment decisions, follow-up examinations and interventions are taken by the radiation oncologist, relying on a shared decision-making process taken within the tumor board, which is considered a fundamental instrument to improve patient care in this setting [36].

\section{Conclusions}

The present study has some limitations. Sampling and non-response biases could be present, due to the response rate of $43 \%$ and the unknown characteristics of those who did not respond, which did not allow us to control for the decreased chance for some of the potential respondents to be surveyed and for a selected response trend for certain participants. Order bias could also be present, with an influence of the format employed on the chance to provide a specific response. The study relied on self-reporting, known to be potentially misaligned with reality and leading to potential recall and response biases. In this sense, performance-based instruments or structured interviews, less influenced on the individuals' awareness, are considered more reliable options in addition to traditional self-reported measures.

Nevertheless, a positive degree of concordance with national and international guidelines is reported in the present survey amongst radiation oncologists treating anal cancer patients in Italy. However, several differences have been observed in terms of RT prescription doses, HIV screening and the involvement of gynecologists in the initial patient's assessment. These data underline the need for a consensus to further harmonize the 
management of anal cancer patients in the country. The Study Group for Gastrointestinal Tumors at AIRO is presently planning to set up a project based on the Delphi consensus methodology, to homogenize diagnosis and treatment for anal cancer patients in Italy in order to mitigate the differences in patient management outlined by the present survey. After the generation of a consensus, the Italian radiation oncology community is also planning to register all anal cancer cases within a shared platform in the frame of a prospective observational cohort study.

Supplementary Materials: The following are available online at https:/ / www.mdpi.com/article/10 $.3390 /$ medicina57121342/s1, Questionnaire S1: full text questionnaire.

Author Contributions: Conceptualization, P.F. and G.M. (Giovanna Mantello); methodology, G.C. and G.M. (Giampaolo Montesi); software, S.M.; validation, A.A., T.C. and F.A.; formal analysis, L.C.; investigation, G.M. (Giampaolo Montesi) and E.P.; resources, M.L.; data curation, M.R.N. and F.M.; writing—original draft preparation, P.F.; writing—review and editing, G.C., G.M. (Giovanna Mantello), A.A., L.C. and S.M.; visualization, M.K.; supervision, D.G., M.A.G. and F.V. All authors have read and agreed to the published version of the manuscript.

Funding: This research received no external funding.

Institutional Review Board Statement: The Scientific Committee and Board of the AIRO critically revised and finally approved the present project (Nr. 38/2021; approved on 20 March 2021).

Informed Consent Statement: Not applicable.

Data Availability Statement: Data are available upon request to the corresponding author.

Acknowledgments: The Authors would like to thank the Scientific Committee and Board of the AIRO for the critical revision and the final approval of the manuscript (Nr. 38/2021). The authors would also like to thank Michela Cozzaglio and the Secretariat of AIRO for administrative and technical support.

Conflicts of Interest: The authors declare no conflict of interest.

\section{References}

1. James, R.D.; Glynne-Jones, R.; Meadows, H.M.; Cunningham, D.; Myint, A.S.; Saunders, M.P.; Maughan, T.; McDonald, A.; Essapen, S.; Leslie, M.; et al. Mitomycin or cisplatin chemoradiation with or without maintenance chemotherapy for treatment of squamous-cell carcinoma of the anus (ACT II): A randomised, phase 3, open-label, $2 \times 2$ factorial trial. Lancet Oncol. 2013, 14, 516-524. [CrossRef]

2. $\quad$ Ajani, J.A.; Winter, K.A.; Gunderson, L.L.; Pedersen, J.; Benson, A.B., III; Thomas, C.R., Jr.; Mayer, R.J.; Haddock, M.G.; Rich, T.A.; Willett, C. Fluorouracil, mitomycin, and radiotherapy vs. fluorouracil, cisplatin, and radiotherapy for carcinoma of the anal canal: A randomized controlled trial. JAMA 2008, 299, 1914-1921. [CrossRef] [PubMed]

3. Franco, P.; Mistrangelo, M.; Arcadipane, F.; Munoz, F.; Sciacero, P.; Spadi, R.; Migliaccio, F.; Angelini, V.; Bombaci, S.; Rondi, $\mathrm{N}$; i et al. Intensity-modulated radiation therapy with simultaneous integrated boost combined with concurrent chemotherapy for the treatment of anal cancer patients: 4-year results of a consecutive case series. Cancer Investig. 2015, 33, 259-266. [CrossRef] [PubMed]

4. Rao, S.; Sclafani, F.; Eng, C.; Adams, R.A.; Guren, M.G.; Sebag-Montefiore, D.; Benson, A.; Bryant, A.; Peckitt, C.; Segelov, E.; et al. International rare cancers initiative multicenter randomized phase II trial of cisplatin and fluorouracil versus carboplatin and paclitaxel in advanced anal cancer: InterAAct. J. Clin. Oncol. 2020, 38, 2510-2518. [CrossRef]

5. Kim, S.; Francois, E.; André, T.; Samalin, E.; Jary, M.; El Hajbi, F.; Baba-Hamed, N.; Pernot, S.; Kaminsky, M.C.; Bouché, O.; et al. Docetaxel, cisplatin and fluorouracil chemotherapy for metastastic or unresectable locally recurrent anal squamous cell carcinoma (Epitopes-HPV02): A multicenter, single-arm, phase 2 study. Lancet Oncol. 2018, 19, 1094-1106. [CrossRef]

6. Franco, P.; Arcadipane, F.; Ragona, R.; Mistrangelo, M.; Cassoni, P.; Munoz, F.; Rondi, N.; Morino, M.; Racca, P.; Ricardi, U. Volumetric modulated arc therapy (VMAT) in the combined modality treatment of anal cancer patients. Br. J. Radiol. 2016, 89, 2015832. [CrossRef]

7. Arcadipane, F.; Franco, P.; Ceccarelli, M.; Furfaro, G.; Rondi, N.; Trino, E.; Martini, S.; Iorio, G.C.; Mistrangelo, M.; Cassoni, P.; et al. Image-guided IMRT with simultaneous integrated boost as per RTOG 0529 for the treatment of anal cancer. Asia Pac. J. Clin. Oncol. 2018, 14, 217-223. [CrossRef]

8. Rao, S.; Guren, M.G.; Khan, K.; Brown, G.; Renehan, A.G.; Steigen, S.E.; Deutsch, E.; Martinelli, E.; Arnold, D. Anal cancer: ESMO clinical practice guidelines for diagnosis, treatment and follow up. Ann. Oncol. 2021, 32, 1087-1100. [CrossRef]

9. Glynne-Jones, R.; Nilsson, P.J.; Aschele, C.; Goh, V.; Peiffert, D.; Cervantes, A.; Arnold, D. Anal cancer: ESMO-ESSO-ESTRO clinical practice guidelines for diagnosis, treatment and follow-up. Radiother Oncol. 2014, 111, 330-339. [CrossRef] 
10. Anal IMRT Guidance. Available online: http:/ / analimrtguidance.co.uk/ (accessed on 26 September 2019).

11. NCCN Guideline Anal Cancer. Available online: https://www.nccn.org/professionals/physician_gls/pdf/anal.pdf (accessed on 26 September 2019).

12. Ng, M.; Leong, T.; Chander, S.; Chu, J.; Kneebone, A.; Carroll, S.; Wiltshire, K.; Ngan, S.; Kachnic, L. Australasian gastrointestinal trials group (AGITG) contouring atlas and planning guidelines for intensity-modulated radiotherapy in anal cancer. Int. J. Radiat. Oncol. 2012, 83, 1455-1462. [CrossRef]

13. Associazione Italiana Radioterapia Oncologica. Gruppo di Studio per i Tumori Gastrointestinali. La Radioterapia dei Tumori Gastrointestinali. Indicazioni e Criteri Guida. Edizione Tascabile. 2014. Available online: www.radioterapiaitalia.it/linee-guidaraccomadazioni/linee-guida-della-disciplina (accessed on 27 July 2021).

14. Caravatta, L.; Mantello, G.; Valvo, F.; Franco, P.; Gasparini, L.; Rosa, C.; Slim, N.; Manfrida, S.; De Felice, F.; Gerardi, M.A.; et al Radiotherapy with intensity-modulated (IMRT) techniques in the treatment of anal carcinoma (RAINSTORM): A multicenter study on behalf of AIRO (Italian Association of Radiotherapy and Clinical Oncology) Gastrointestinal Study Group. Cancers 2021, 13, 1902. [CrossRef]

15. Eysenbach, G. Improving the quality of web surveys: The checklist for reporting results of internet E-surveys (CHERRIES). J. Med. Internet Res. 2004, 6, e34. [CrossRef]

16. Martin, D.; von der Grun, J.; Rodel, C.; Fokas, E. Management of anal cancer patients-A pattern of care analysis in Germanspeaking countries. Radiat. Oncol. 2020, 15, 122. [CrossRef]

17. Gerum, S.; Iglseder, W.; Schmid, R.; Peterka, K.; Knoche-Abulesz, T.H.; Harl, P.; Schwaiger, S.; Reiter, I.; Salinger, J.; Venhoda, C.; et al. Practice of radiation therapy for anal cancer in Austria-A survey on behalf of the Austrian radiation oncology society gastrointestinal tumor group (ÖGRO-GIT). Strahelenther Onkol. 2021, 197, 953-961. [CrossRef]

18. Jones, M.; Hruby, G.; Solomon, M.; Rutherford, N.; Martin, J. The role of FDG-PET in the initial staging and response assessment of anal cancer: A systematic review and meta-analysis. Ann. Surg. Oncol. 2015, 22, 3574-3578. [CrossRef]

19. Arcadipane, F.; Silvetti, P.; Olivero, F.; Gastino, A.; De Luca, V.; Mistrangelo, M.; Cassoni, P.; Racca, P.; Gallio, E.; Lesca, A.; et al. Bone marrow-sparing IMRT in anal cancer patiejts undergoing concurrent chemo-radiation: Results of the first phase of a prospective phase II trial. Cancers 2020, 12, 3306. [CrossRef]

20. Arcadipane, F.; Solvetti, P.; Olivero, F.; Gastino, A.; Carlevato, R.; Chiovatero, I.; Spinelli, L.; Mistrangelo, M.; Cassoni, P.; Ritorto, G.; et al. Concurrent chemoradiation in anal cancer patients delivered with bone marrow-sparing IMRT: Final results of a prospective phase II trial. J. Pers. Med. 2021, 11, 427. [CrossRef]

21. Martin, D.; Balermps, P.; Fokas, E.; Rodel, C.; Yildirim, M. Are there HIV-specific differences for anal cancer patients treated with standard chemoradiation in the era of combined antiretroviral therapy? Clin. Oncol. 2017, 29, 248-255. [CrossRef]

22. Sun, G.; Dong, X.; Tang, X.; Qu, H.; Zhang, H.; Zhao, E. The prognostic value of HPV combined p16 status in patients with anal squamous cell carcinoma: A meta-analysis. Oncotarget 2018, 9, 8081-8088. [CrossRef]

23. Kachnic, L.A.; Winter, K.; Myerson, R.J.; Goodyear, M.D.; Willins, J.; Esthappan, J.; Haddock, M.G.; Rotman, M.; Parikh, P.J.; Safran, H.; et al. RTOG 0529: A phase 2 evaluation of dose-painted intensity modulated radiation therapy in combination with 5-fluorouracil and mytomicin-C for the reduction of acute morbidity in carcinoma of the anal canal. Int. J. Radiat. Oncol. Biol. Phys. 2013, 86, 27-33. [CrossRef]

24. Mitra, D.; Hong, T.S.; Horick, N.; Rose, B.; Drapek, L.N.; Blaszkowsky, L.S.; Allen, J.N.; Kwak, E.L.; Murphy, J.E.; Clark, J.W.; et al. Long-term outcomes and toxicities of a large cohort of anal cancer patients treated with dose-painted IMRT per RTOG 0529. Adv. Radiat. Oncol. 2017, 2, 110-117. [CrossRef]

25. Franco, P.; De Bari, B.; Arcadipane, F.; Lepinoy, A.; Ceccarelli, M.; Furfaro, G.; Mistrangelo, M.; Cassoni, P.; Valgiusti, M.; Passardi, A.; et al. Comparing simultaneous integrated boost vs sequential boost in anal cancer patients: Results of a retrospective observational study. Radiat. Oncol. 2018, 13, 172. [CrossRef]

26. Leon, O.; Guren, M.; Hagberg, O.; Glimelius, B.; Dahl, O.; Havsteen, H.; Naucler, G.; Svensson, C.; Tvei, K.M.; Jakobsen, A.; et al. Anal carcinoma-Survival and recurrence in a large cohort of patients treated according to Nordic guidelines. Radiother. Oncol. 2014, 113, 352-358. [CrossRef]

27. Peiffert, D.; Tournier-Rangeard, L.; Gérard, J.-P.; Lemanski, C.; François, E.; Giovannini, M.; Cvitkovic, F.; Mirabel, X.; Bouché, O.; Luporsi, E.; et al. Induction chemotherapy and dose intensification of the radiation boost in locally advanced anal canal carcinoma: Final analysis of the randomized UNICANCER ACCORD 03 trial. J. Clin. Oncol. 2012, 30, 1941-1948. [CrossRef]

28. Faivre, J.-C.; Peiffert, D.; Vendrely, V.; Lemanski, C.; Hannoun-Levi, J.-M.; Mirabel, X.; Stanbury, T.; Salleron, J.; Guillemin, F. Prognostic factors of colostomy free survival in patients presenting with locally advanced anal canal carcinoma: A pooled analysis of two prospective trials (KANAL 2 and ACCORD 03). Radiother. Oncol. 2018, 129, 463-470. [CrossRef]

29. Sebag-Montefiore, D.; Adams, R.; Bell, S.; Berkman, L.; Gilbert, D.C.; Glynne-Jones, R.; Goh, V.; Gregory, W.; Harrison, M.; Kachnic, L.A.; et al. The development of an umbrella trial (PLATO) to address radiation therapy dose questions in the locoregional management of squamous cell carcinoma of the anus. Int. J. Radiat. Oncol. Biol. Phys. 2016, 96, E164-E165. [CrossRef]

30. Shakir, R.; Adams, R.; Cooper, R.; Downing, A.; Geh, I.; Gilbert, D.; Jacobs, C.; Jones, C.; Lorimer, C.; Namelo, W.C.; et al. Patterns and predictors of relapse following radiacal chemoradiation therapy delivered using intensity modulated radiation therapy with simultanoues integrated boost in anal squamous cell carcinomas. Int. J. Radiat. Oncol. Biol. Phys. 2020, 106, 329-339. [CrossRef]

31. White, E.C.; Goldman, K.; Aleshin, A.; Lien, W.W.; Rao, A.R. Chemoradiotherapy for squamous cell carcinoma of the anal canal: Comparison of one versus two cycles of mytomicin-C. Radiother. Oncol. 2015, 117, 240-245. [CrossRef] 
32. Franco, P.; Ragona, R.; Arcadipane, F.; Mistrangelo, M.; Cassoni, P.; Rondi, N.; Morino, M.; Racca, P.; Ricardi, U. Dosimetric predictors of acute hematologic toxicity during concurrent intensity-modulated radiotherapy and chemotherapy for anal cancer. Clin. Transl. Oncol. 2017, 19, 67-75. [CrossRef]

33. Jones, C.M.; Adams, R.; Downing, A.; Glynne-Jones, R.; Harrison, M.; Hawkins, M.; Sebag-Montefiore, D.; Adams, R.; Downing, A.; Glynne-Jones, R.; et al. Toxicity, tolerability, and complicance of concurrent capecitabine or 5-fluorouracil in radical management of anal cancer with single-dose mitomycin-C and intensity modulated radiation therapy: Evaluation of a national cohort. Int. J. Radiat. Oncol. Biol. Phys. 2018, 101, 1202-1211. [CrossRef]

34. Holliday, E.B.; Lester, S.C.; Harmsen, S.; Eng, C.; Haddock, M.G.; Krishnan, S.; Das, P.; Hallemeier, C.L. Extended-field chemoradiation therapy for definitive treatment of anal canal squamous cell Carcinoma involving the para-aortic lymph nodes. Int. J. Radiat. Oncol. Biol. Phys. 2018, 102, 102-108. [CrossRef] [PubMed]

35. Glynne-Jones, R.; Sebag-Montefiore, D.; Meadows, H.M.; Cunningham, D.; Begum, R.; Adab, F.; Benstead, K.; Harte, R.J.; Stewart, J.; Beare, S.; et al. Best time to assess complete clinical response after chemoradiotherapy in squamous cell carcinoma of the anus (ACT II): A post-hoc analysis of randomised controlled phase 3 trial. Lancet Oncol. 2017, 18, 347-356. [CrossRef]

36. Guren, M.G.; Sebag-Montefiore, D.; Franco, P.; Johnsson, A.; Segelov, E.; Deutsch, E.; Rao, S.; Spindler, K.L.; Arnold, D. Treatment of squamous cell carcinoma of the anus, unresolved areas and future perspective for research. Perspective of research needs in anal cancer. Clin. Colorect. Cancer 2021, in press. [CrossRef] [PubMed] 